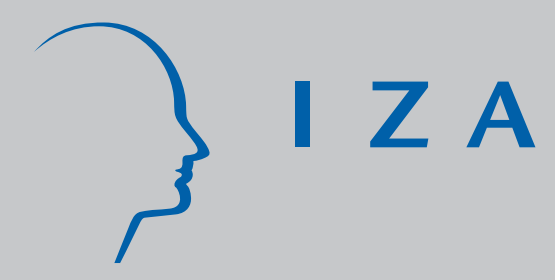

IZADP No. 2651

Full-time Schooling, Part-time Schooling, and Wages:

Returns and Risks in Portugal

Corrado Andini

Pedro Telhado Pereira

March 2007 


\title{
Full-time Schooling, Part-time Schooling, and Wages: Returns and Risks in Portugal
}

\author{
Corrado Andini \\ University of Madeira and CEEAPIA
Pedro Telhado Pereira
University of Madeira, CEEAPIA, CEPR and IZA
Discussion Paper No. 2651
March 2007

IZA

P.O. Box 7240

53072 Bonn

Germany

Phone: +49-228-3894-0
Fax: +49-228-3894-180
E-mail: iza@iza.org

Any opinions expressed here are those of the author(s) and not those of the institute. Research disseminated by IZA may include views on policy, but the institute itself takes no institutional policy positions.

The Institute for the Study of Labor (IZA) in Bonn is a local and virtual international research center and a place of communication between science, politics and business. IZA is an independent nonprofit company supported by Deutsche Post World Net. The center is associated with the University of Bonn and offers a stimulating research environment through its research networks, research support, and visitors and doctoral programs. IZA engages in (i) original and internationally competitive research in all fields of labor economics, (ii) development of policy concepts, and (iii) dissemination of research results and concepts to the interested public.

IZA Discussion Papers often represent preliminary work and are circulated to encourage discussion. Citation of such a paper should account for its provisional character. A revised version may be available directly from the author. 


\section{ABSTRACT}

\section{Full-time Schooling, Part-time Schooling, and Wages: Returns and Risks in Portugal ${ }^{*}$}

The standard wage equation proposed by Mincer (1974) assumes that individuals start working after leaving school, which is not the actual case for many people. Using longitudinal data on Portuguese male workers, former working students, we estimate the total impact of an additional year of full-time schooling on both the mean and the shape of the conditional wage distribution. The same exercise is also performed for part-time schooling. We find that the conditional average earnings return to one year of part-time schooling is much lower than the analogous return to one year of full-time schooling. However, the conditional wage risk implied by one year of part-time schooling is much lower than the analogous risk implied by one year of full-time schooling, thus complicating policy considerations. Nevertheless, we find evidence that the full-time schooling strategy dominates, in conditional wage distribution, the part-time schooling strategy, meaning that the choice of working while enrolled in school does not ultimately pay.

JEL Classification: $\quad$ I21, J31, C23

Keywords: $\quad$ working students, return to schooling, wage level, panel data

Corresponding author:

Corrado Andini

Universidade da Madeira

Campus da Penteada

9000-390 Funchal

Portugal

E-mail: andini@uma.pt

\footnotetext{
* The authors gratefully acknowledge financial support from the European Commission (EDWIN Project, HPSE-CT-2002-00108).
} 


\section{Introduction}

The seminal work by Jacob Mincer (1974) on Schooling, Experience and Earnings is the starting point of a large body of literature dealing with the estimation of an individual-level wage equation where the logarithm of hourly earnings is explained by schooling years, labour-market experience and experience squared.

The Mincerian framework is a corner-stone of modern education economics, although it has some limitations. One of the limitations of the framework has to do with the hypothesis that individuals start working after leaving school, which is quite not the case for many people in many countries. Indeed, as stressed by Audrey Light (2001, p. 65), “students often accumulate substantial work experience before leaving school”.

A recent report summarizing the experiences of eight European countries in 2000 shows that the ratio of working students to total students varies from 48 percent in France to 77 percent in the Netherlands (see Häkkinen, 2004). Despite the numerical relevance of working students, the first attempt of controlling for in-school work experience when estimating the Mincerian return to schooling is relatively recent. Light (2001) uses data from the US National Longitudinal Survey of Youth and finds that the lack of control for in-school work experience implies a substantial overestimation of the Mincerian return to schooling.

Of course, the study by Audrey Light is not the only, nor the first study in the field. On the contrary, the field is relatively rich in contributions aiming at measuring the earnings return to in-school work. From a theoretical point of view, the academic debate on this issue presents two clear and opposite views. On the one hand, there are those who maintain that working while enrolled in school is positive because it fosters the development of personal responsibility and good work-habits. On the other hand, there 
are those who criticize this practice because it interferes with learning activities at school, delaying schooling achievements (see Schoenhals et al., 1998 for a review). As for the theory, the empirical evidence accumulated in the field so far is also mixed. Many authors find evidence in favour of in-school work in terms of substantial higher wages later in life. Nevertheless, a recent study by Hotz et al. (2002) questions this whole body of evidence because unobserved heterogeneity and sample selectivity are not controlled for. Indeed, the authors find that controlling for these two factors completely eliminates the positive impact of in-school work on future earnings.

Another striking feature of the empirical literature, at academic level, is concerning with being almost exclusively related to the case of the United States. A recent paper by Häkkinen (2004) is one of the first attempts to fill the gap between the European Union and the United States. The author asks whether it pays to work while enrolled in school in Finland, with results that are in line with those proposed by Hotz et al. (2002). Summarizing, the existing literature suggests that the earnings return to an additional year of full-time schooling is much higher than the earnings return to an additional year of either in-school work or part-time schooling, which are two sides of the same coin. However, despite a relatively high number of contributions, we believe that some important information is still missing in the existing literature. This information is concerning with the estimation of the wage risk of full-time education compared to parttime education. As a matter of example, if an additional year of full-time schooling pays more than an additional year of part-time schooling in terms of average future wage returns, the latter may involve less wage risk than the first. That is, there may be a tradeoff between risk and return that the literature has not explored yet. 
Starting from the latter consideration, this paper attempts to identify the total average impact of both full-time schooling and part-time schooling on earnings, also comparing associated wage risks. Hence, from an academic point of view, our paper contributes to the ongoing debate on the return-risk link in education (among others, see Levhari and Weiss, 1974; Pereira and Martins, 2002; Hogan and Walker, 2003; Harmon et al., 2003; Hartog et al., 2004; Christiansen et al., 2006; Andini, 2007a).

Specifically, we aim at answering, in a different way than suggested so far, the question of whether the choice of working while enrolled in school actually pays. As we will see, based on Portuguese data, the answer is complex. Considering average wage returns only, we answer "no". Therefore, the answer is in line with earlier findings by both Hotz et al. (2002) and Häkkinen (2004). However, considering wage risks only, we answer "yes". Therefore, considering both returns and risks, the answer to our main research question may appear controversial. Nevertheless, we find that the full-time schooling strategy dominates, in conditional wage distribution, the part-time schooling strategy, thus providing an economic reason for ultimately answering "no".

\section{Theoretical background}

If the average wage return to full-time schooling is clearly higher than the average wage return to part-time schooling as suggested by the existing literature, why does the phenomenon of in-school work continue to exist? There are multiple ways of answering this question. For the purpose of this paper, we find interesting the exercise of focusing on return-risk considerations, using a simple model of choice based on unconditional moments. 
Let us think at full-time schooling and part-time schooling as two different assets providing random wage returns, say $\tilde{\mathrm{W}}_{1} \sim\left(\beta_{1}, \sigma_{1}^{2}\right)$ and $\tilde{\mathrm{W}}_{2} \sim\left(\beta_{2}, \sigma_{2}^{2}\right)$ respectively. Analogously, let as think at schooling as a portfolio of these two assets providing a random wage return, say $\tilde{\mathrm{W}} \sim\left(\beta, \sigma^{2}\right)$.

Further, following the existing evidence, let us assume that full-time schooling provides a higher average wage return than part-time schooling, i.e. $\beta_{1}>\beta_{2}$. In addition, let us assume that the correlation coefficient between the wage returns to full-time schooling and part-time schooling is equal to $\rho$. Finally, let us suppose that an individual cares about the mean $\beta$ and the variance $\sigma^{2}$ of the random wage return of the schooling portfolio, i.e. the individual utility function is specified as $U\left(\beta, \sigma^{2}\right)$ with $U^{\prime}(\beta)>0$ and $\mathrm{U}^{\prime}\left(\sigma^{2}\right)<0$.

Under the hypothesis that an individual maximizes his/her mean-variance utility function, which share of schooling years should be optimally invested in full-time education and in part-time education?

To answer this question, we must first notice that the individual faces the following constraint:

(1) $\quad \tilde{\mathrm{W} S}=\tilde{\mathrm{W}}_{1} \mathrm{~S}_{1}+\tilde{\mathrm{W}}_{2} \mathrm{~S}_{2}$

where $S_{1}$ is the number of schooling years invested in full-time schooling, and $S_{2}$ is the number of schooling years invested in part-time schooling. For sake of simplicity, we assume that the total number of schooling years $\mathrm{S}$ is determined outside the model. 
Expression (1) simply tells us that the total random wage return provided by S years of schooling must be equal the total random wage return provided by $S_{1}$ years of full-time schooling plus the total random wage return provided by $S_{2}$ years of part-time schooling.

Dividing both sides of expression (1) by S, we obtain the following expression:

(2) $\quad \tilde{\mathrm{W}}=\mathrm{x}_{1} \tilde{\mathrm{W}}_{1}+\mathrm{x}_{2} \tilde{\mathrm{W}}_{2}$

where $\mathrm{x}_{1}=\frac{\mathrm{S}_{1}}{\mathrm{~S}}$ is the share of schooling years invested in full-time education, while $\mathrm{x}_{2}=1-\mathrm{x}_{1}$ is the share of schooling years invested in part-time education (notice that the expression $\mathrm{S}=\mathrm{S}_{1}+\mathrm{S}_{2}$ holds).

Using (2), we can easily show that both $\beta=E(\tilde{W})$ and $\sigma^{2}=\operatorname{VAR}(\tilde{W})$ depend on $x_{1}$, according to the following expressions:

(3) $\quad \beta=x_{1} \beta_{1}+\left(1-x_{1}\right) \beta_{2}$

and

(4) $\sigma^{2}=x_{1}^{2} \sigma_{1}^{2}+\left(1-x_{1}\right)^{2} \sigma_{2}^{2}+2 x_{1}\left(1-x_{1}\right) \rho \sigma_{1} \sigma_{2}$. 
Therefore, the economic problem of the individual who chooses the optimal share of schooling years to be invested in full-time schooling in order to maximize his/her meanvariance utility function turns out to be the following simple one:

(5)

$$
\operatorname{Max}_{0 \leq x_{1} \leq 1} U\left(\beta, \sigma^{2}\right) .
$$

Under appropriate parameters' conditions, problem (5) admits the following an internal solution:

(6) $\quad \mathrm{x}_{1} *=\frac{\frac{\beta_{1}-\beta_{2}}{2 \alpha}+\sigma_{2}^{2}-\rho \sigma_{1} \sigma_{2}}{\sigma_{1}^{2}+\sigma_{2}^{2}-2 \rho \sigma_{1} \sigma_{2}}$

where $\alpha=-\frac{\mathrm{U}^{\prime}\left(\sigma^{2}\right)}{\mathrm{U}^{\prime}(\beta)}$ represents a degree of wage risk aversion.

This simple model, mainly inspired by an earlier model for skills developed by Hartog and Vijverberg (2006), helps to show that, although the average wage return of full-time education is higher than the average wage return to part-time education $\left(\beta_{1}>\beta_{2}\right)$, an individual may optimally choose to spend a share of schooling years as a working student, say $\mathrm{x}_{1}{ }^{*}=0.6$ implying $\mathrm{x}_{2}{ }^{*}=0.4$, because the wage risks involved in both fulltime schooling and part-time schooling also matter for the choice (among other things). Therefore, it is important to estimate not only the conditional average wage returns to both full-time schooling and part-time schooling but also the conditional wage risk 
involved in both full-time education and part-time education. This is what we do in the next section.

\section{Data, empirical model and results}

We use data on Portuguese male workers from the European Community Household Panel, from the wave of 1994 to the wave of 2001, and focus on a sample of former working students. The sample is described in Table 1.

\section{Table 1 here}

Using individual-level panel data, the Mincerian model suggests the estimation of the following wage equation:

(7) $\quad \ln w_{i t}=\beta_{0}+\beta_{1}$ school $_{i}+\beta_{2}$ potwork $_{i t}+\beta_{3}$ potwork $_{i t}^{2}+\xi_{i t}$

where $\ln w$ represents the natural logarithm of hourly earnings, school represents schooling years, and potwork stands for potential work-experience computed as usual (individual age minus schooling years minus six). Letter $i$ represents the individual dimension, while letter $t$ represents the time dimension (annual, in our data-set).

For the purpose of this paper, we suggest two simple departures from the above empirical setting. First, rather than potential labour-market experience, we compute actual full-time labour-market experience. The latter is given by the number of full-time working years actually accumulated by an individual at the date of the interview. Let us 
label this variable as fullwork. Second, we distinguish between years of full-time schooling, labelled as fullschool, and years of part-time schooling, labelled as partschool .

In addition, as usual with longitudinal data, instead of just considering a fixed common intercept, we allow for the existence of individual-specific intercepts in order to capture individual heterogeneity, due to different abilities, costs of borrowing, labour-market luck, and so on. Moreover, we use wave dummies to keep year heterogeneity into account. Therefore, we estimate the following empirical model:

$$
\ln w_{i t}=\beta_{0}+\beta_{1} \text { fullschool }_{i}+\beta_{2} \text { partschool }_{i}+\beta_{3} \text { fullwork }_{i t}+\beta_{4} \text { fullwork }_{i t}^{2}+\beta_{i}+\beta_{t}+\xi_{\text {it }}
$$

using the random-effects estimator (RE) and the between-effects estimator (BE). Further, we provide pulled estimates based on the ordinary-least-squares estimator (OLS), thus disregarding the longitudinal structure of the data-set. Finally, in order to evaluate and compare the wage risks implied by both full-time education and part-time education, we also use the quantile-regression estimator (QR) due to Koenker and Bassett (1978). Specifically, we provide estimates for a model of the following type:

$$
\ln w_{i t}=\beta_{0 \theta}+\beta_{1 \theta} \text { fullschool }_{i}+\beta_{2 \theta} \text { partschool }_{i}+\beta_{3 \theta} \text { fullwork }_{i t}+\beta_{4 \theta} \text { fullwork }_{i t}^{2}+\beta_{t \theta}+\xi_{i t \theta}
$$

where $\theta$ represents the conditional wage-distribution decile. Hence, following a seminal contribution by Buchinsky (1994) for the United States, we contribute to the existing research on within-groups wage inequality in Portugal (among others, see 
Machado and Mata, 2001; Hartog et al., 2001; Martins and Pereira, 2004; Andini, 2007b).

Notice that we focus on the estimation of total returns, meaning that all direct and indirect effects of education, either full-time or part-time, on earnings are captured by just two coefficients, $\beta_{1}$ and $\beta_{2}$ (see Pereira and Martins, 2004; Andini, 2007c).

Estimation results on conditional average returns, based on the RE estimator, are reported in Table 2. Results based on the BE estimator are presented in Table 3. As we may notice, the earnings return to an additional year of full-time schooling is much higher than the corresponding return to part-time schooling. A formal test also confirms that the two coefficients are statistically different. The magnitude of this difference is around 7 percent points. In addition, Table 4 shows that the OLS estimator is fully in line with the RE estimator and with the BE estimator, suggesting that the role played by individual unobserved heterogeneity, in our specific application, is likely to be relatively small.

Table 2 here

Table 3 here

Table 4 here

Figure 1 presents quantile-regression estimates of $\beta_{1}$ and $\beta_{2}$ at each decile of the conditional wage distribution. The graph in Figure 1 is obtained using a specific STATA module written by Azevedo (2004). We measure the wage risk as usual in the literature, i.e. as difference between the return at the ninth decile and the return at the first decile. Notice, in Table 5, that the wage risk involved in full-time education is 
almost 4 times bigger than the wage risk involved in part-time education, meaning that there is clear evidence of a trade-off between risk and return. Nevertheless, the return to an additional year of full-time schooling at the lowest decile is higher than the return to an additional year of part-time schooling at the highest decile, meaning that the full-time schooling strategy dominates, in conditional wage distribution, the part-time schooling strategy.

Figure 1 here

Table 5 here

\section{Conclusions}

In line with what one may reasonably expect from previous research, we find that the strategy of studying and working at the same time pays, on average, less than the strategy of studying only. The magnitude of the difference is large and should not be disregarded by educational policy-makers in Portugal. The mean earnings return to one additional year of full-time schooling is four times larger than the mean earnings return to one additional year of part-time schooling. This suggests that the choice of working while enrolled in school is not worth at all, in terms of future average labour-market rewards, because one year of full-time schooling provides the same average total return as four years of part-time schooling.

If these results would imply the same wage risk, then our policy recommendations would be relatively easy and twofold. First, universities should strongly limit the access of students to special curricula for working students. Second, public funds supporting the schooling activity of those who cannot finance their studies by themselves should be 
increased. This public investment will be repaid by higher average national earnings (and higher tax receipts) in the future.

However, our results do not imply the same underlying wage risk, thus complicating policy considerations. Indeed, the wage risk of part-time schooling is much lower than the wage risk of full-time schooling, implying that that educational policies fostering full-time education in Portugal would significantly increase within-groups wage inequality in the future. Putting it differently, the existence of different wage risks associated with full-time education and part-time education provides an economic reason for the existence of special curricula for working students, otherwise not justified by the empirical evidence on the average wage returns to part-time schooling.

Nevertheless, since the full-time schooling strategy dominates, in conditional wage distribution, the part-time schooling strategy, our final answer to the main research question of this paper is not controversial. Does the choice of working while enrolled in school actually pay? We answer "no”.

A final note is about the fact that the Portuguese working students continue to exist (representing, on average, around 27 percent of former students in our data-set), although our analysis suggests that part-time schooling does not ultimately pay for being associated with a dominated conditional wage distribution. Hence, the reader may wonder whether our results are at odds with the evidence of existing working students. Again, the answer is "no" and the reasons are multiple. First, we estimate ex-post returns and risks while people make their choices based on ex-ante returns and risks (which cannot be estimated because times-series data are only available for truly financial assets). Second, the choice of part-time schooling not only depends on the return-risk combination but also on the individual degree of risk aversion (although we 
control for individual unobserved heterogeneity). Third, the paper disregards a number of financial issues which are likely to affect the part-time schooling choice, such as borrowing constraints, imperfect capital markets, university fees, scholarships, and so on. Forth, there are many non-financial factors that also affect the allocation of time between work and study. Finally, our results are consistent with 2005 data showing that Portugal has the lowest percentage of higher-education working students in a sample of eleven European countries. The share is around 20 percent in Portugal, which is ten percentage points lower than the share of the country with the second lowest share, i.e. Italy with 30 percent (HIS, 2005). 


\section{REFERENCES}

Andini, C. (2007a) On the Return-Risk Link in Education, Applied Economics Letters, forthcoming.

Andini, C. (2007b) The Total Impact of Schooling on Within-Groups Wage Inequality in Portugal, Applied Economics Letters, forthcoming.

Andini, C. (2007c) Returns to Education and Wage Equations: a Dynamic Approach, Applied Economics Letters, forthcoming.

Azevedo, J.P. (2004) GRQREG: Stata Module to Graph the Coefficients of a Quantile Regression, Statistical Software Components, Department of Economics, Boston College.

Buchinsky, M. (1994) Changes in the U.S. Wage Structure 1963-1987: Application of Quantile Regression, Econometrica, 62(2), 405-458.

Christiansen, C., Joensen, J.S. and Nielsen, H.S. (2006) The Risk-Return Trade-Off in Human Capital Investment, IZA Discussion Papers, ${ }^{\circ}$ 1962, Institute for the Study of Labor, February.

Häkkinen, I. (2004) Working While Enrolled in a University: Does it Pay?, Department of Economics Working Papers, $\mathrm{n}^{\circ}$ 1, Uppsala University, January.

Harmon, C., Hogan, V. and Walker, I. (2003), Dispersion in the Economic Return to Schooling, Labour Economics, 10(2), 205-214.

Hartog, J., Pereira, P.T. and Vieira, J.A.C. (2001) Changing Returns to Education in Portugal during the 1980s and Early 1990s: OLS and Quantile Regression Estimators, Applied Economics, 33(8), 1021-1037.

Hartog, J., Van Ophem, H., and Bajdechi, S.M. (2004) How Risky Is Investment in Human Capital?, TI Discussion Papers, ${ }^{\circ}$ TI 2004-080/3, Tinbergen Institute, July.

Hartog, J., and Vijverberg, W. (2006) Schools, Skills and Risk, unpublished manuscript, January.

HIS, abb. for Hochschuld-Informations-System (2005) Eurostudent Report 2005, Langenhagen, Poppdruck, available at: <http://www.his.de/Eurostudent/report2005.pdf>.

Hogan, V. and Walker, I. (2003) Education Choice under Uncertainty: Implications for Public Policy, unpublished manuscript, April.

Hotz, V.J., Xu, L.C., Tienda, M., and Ahituv, A. (2002) Are There Returns to the Wages of Young Men from Working While in School?, Review of Economics and Statistics, 84(2), 221-236.

Koenker, R. and Bassett, G. (1978) Regression Quantiles, Econometrica, 46(1), 33-50.

Levhari, D. and Weiss, Y. (1974), The Effect of Risk on the Investment in Human Capital, American Economic Review, 64(6), 950-963.

Light, A. (2001) In-School Work Experience and the Returns to Schooling, Journal of Labor Economics, 19(1), 65-93.

Machado, J.A.F. and Mata, L. (2001) Earnings Functions in Portugal 1982-1994: Evidence from Quantile Regressions, Empirical Economics, 26(1), 115-134.

Martins, P.S. and Pereira, P.T. (2004) Does Education Reduce Wage Inequality? Quantile Regression Evidence from 16 Countries, Labour Economics, 11(3), 355-371. 
Mincer, J. (1974) Schooling, Experience and Earnings, Cambridge, National Bureau of Economic Research.

Pereira, P.T. and Martins, P.S. (2002) Is There a Return-Risk Link in Education?, Economics Letters, 75(1), 31-37.

Pereira, P.T., and Martins, P.S. (2004) Returns to Education and Wage Equations, Applied Economics, 36(6), 525-531.

Schoenhals, M., Tienda, M., and Schneider, B. (1998) The Educational and Personal Consequences of Adolescent Employment, Social Forces, 77(2), 723-761. 
Table 1. Summary sample statistics

\begin{tabular}{|c|c|c|c|c|c|}
\hline Variable | & Obs & Mean & Std. Dev. & Min & $\operatorname{Max}$ \\
\hline lnw | & 3930 & 6.622962 & .6530738 & 3.641526 & 10.0237 \\
\hline fullschool & 3930 & 9.994911 & 4.09041 & 3 & \\
\hline partschool & 3930 & 8. 311196 & 8.247822 & 1 & 48 \\
\hline fullwork & 3930 & 16.3743 & 12.46107 & 0 & \\
\hline
\end{tabular}


Table 2. Random effects

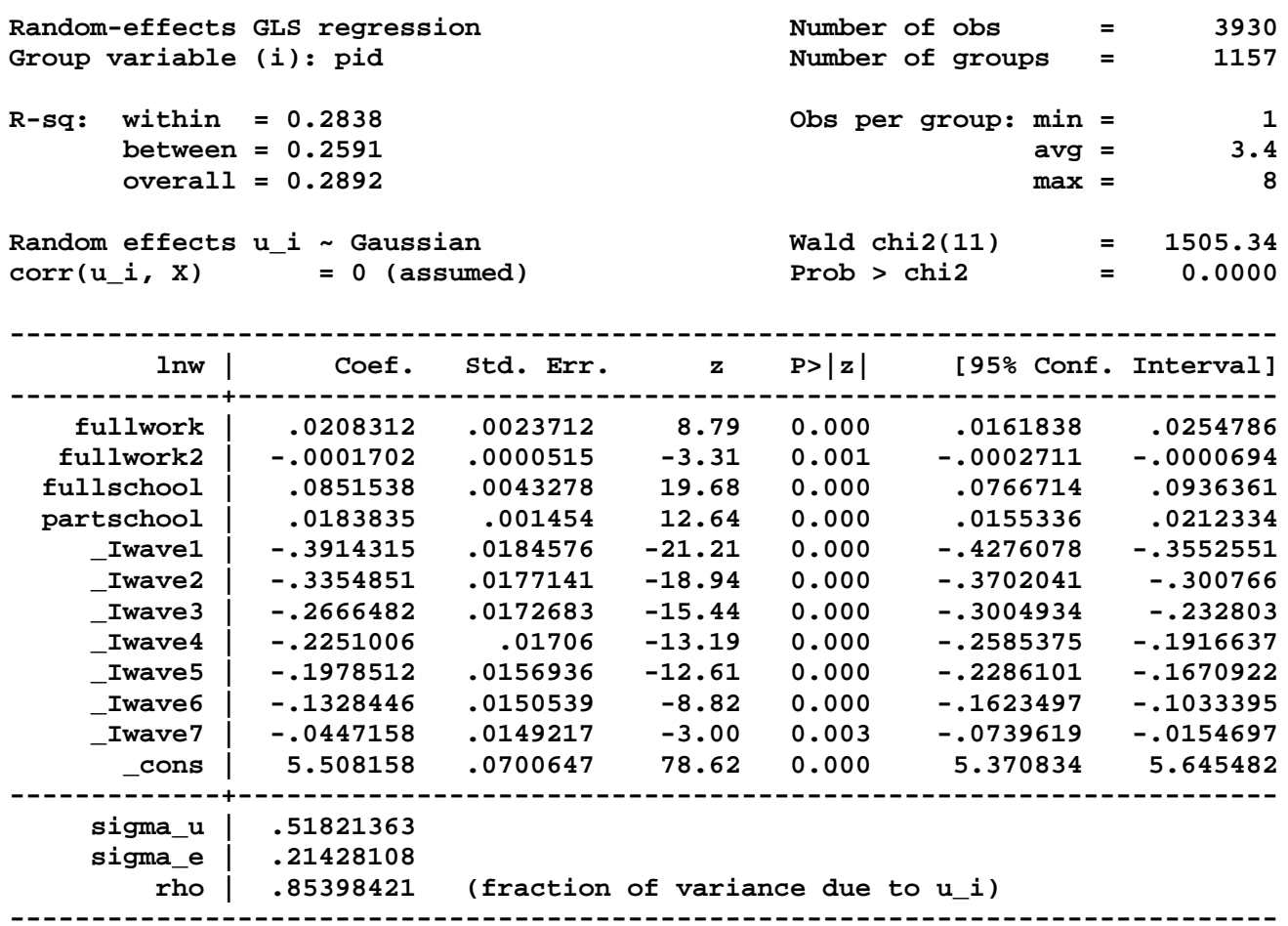

test fullschool = partschool

$\operatorname{chi2}(1)=278.89$

Prob $>$ chi2 $=0.0000$ 
Table 3. Between effects

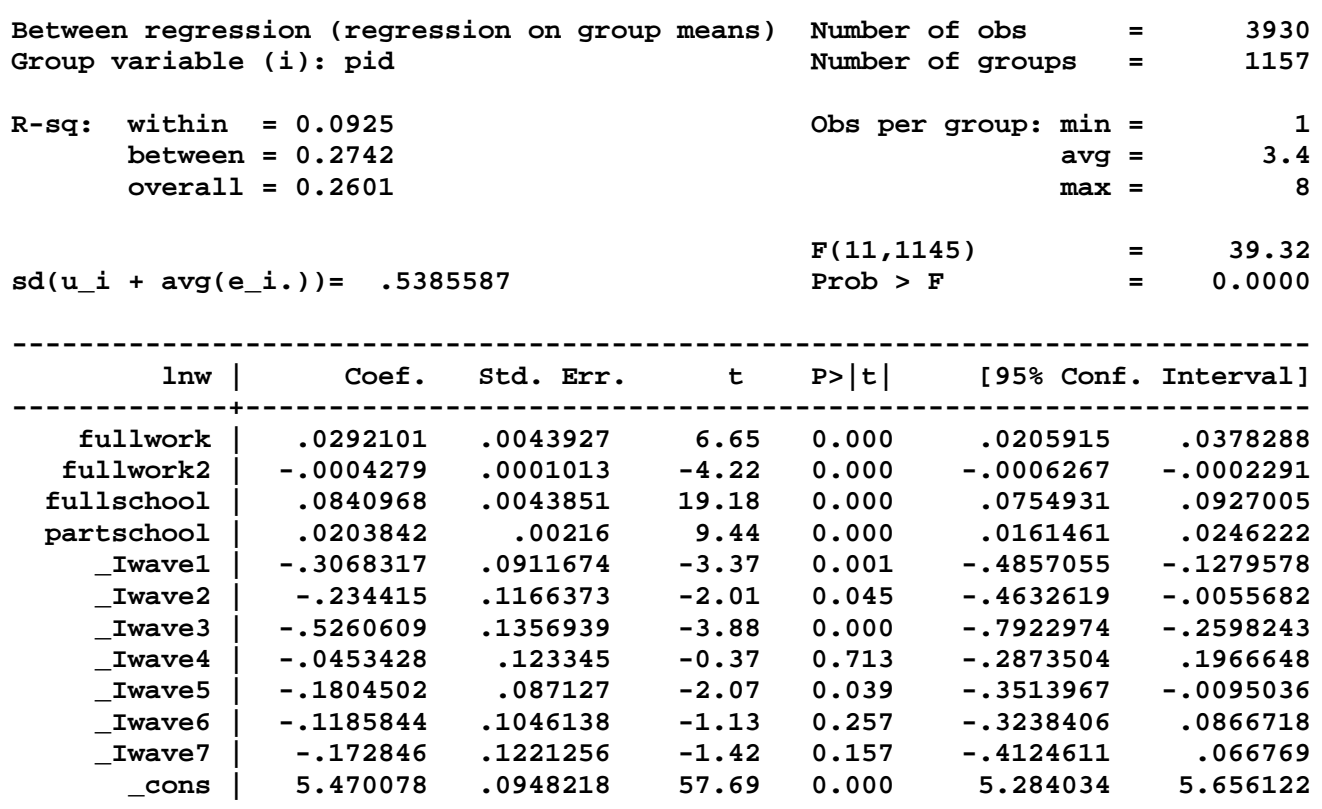

test fullschool $=$ partschool

$F(1,1145)=211.93$

Prob $>F=0.0000$ 
Table 4. Ordinary least squares

Linear regression

Number of obs =

$F(11,3918)=132.64$

Prob $>F=0.0000$

R-squared $\quad=0.2968$

Root MSE $=.54844$

\begin{tabular}{|c|c|c|c|c|c|c|}
\hline lnw & Coef. & $\begin{array}{l}\text { Robust } \\
\text { Std. Err. }\end{array}$ & $\mathrm{t}$ & $P>|t|$ & [95\% Conf. & Interval] \\
\hline & & 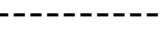 & & & & \\
\hline fullwork & .0339942 & .0023772 & 14.30 & 0.000 & .0293336 & .0386549 \\
\hline fullwork2 & -.0005111 & .0000539 & -9.47 & 0.000 & -.0006168 & -.0004053 \\
\hline fullschool & .0895028 & .0027012 & 33.13 & 0.000 & .084207 & .0947987 \\
\hline partschool & 0191103 & .0011407 & 16.75 & 0.000 & .0168739 & .0213468 \\
\hline Iwave1 & -.3788325 & .0356636 & -10.62 & 0.000 & -.4487534 & -.3089115 \\
\hline Iwave2 & -.3291732 & .0343903 & -9.57 & 0.000 & -.3965977 & - . 2617487 \\
\hline Iwave3 & -.2744965 & .034556 & -7.94 & 0.000 & -.342246 & -.2067471 \\
\hline Iwave 4 & -.2159065 & .0366836 & -5.89 & 0.000 & -.2878273 & - . 1439857 \\
\hline Iwave 5 & -.1646828 & .033975 & -4.85 & 0.000 & -.2312931 & - .0980725 \\
\hline Iwave6 & -.1184582 & .0336265 & -3.52 & 0.000 & -.1843853 & - . 0525312 \\
\hline Iwave7 & -.0412331 & .0353307 & -1.17 & 0.243 & - . 1105014 & .0280352 \\
\hline _cons & 5.420886 & .0456222 & 118.82 & 0.000 & 5.33144 & 5.510331 \\
\hline
\end{tabular}

test fullschool $=$ partschool

$F(1,3918)=674.48$

Prob $>F=0.0000$ 
Table 5. Quantile regression

Simultaneous quantile regression

Number of obs $=$

3930 bootstrap(20) SES

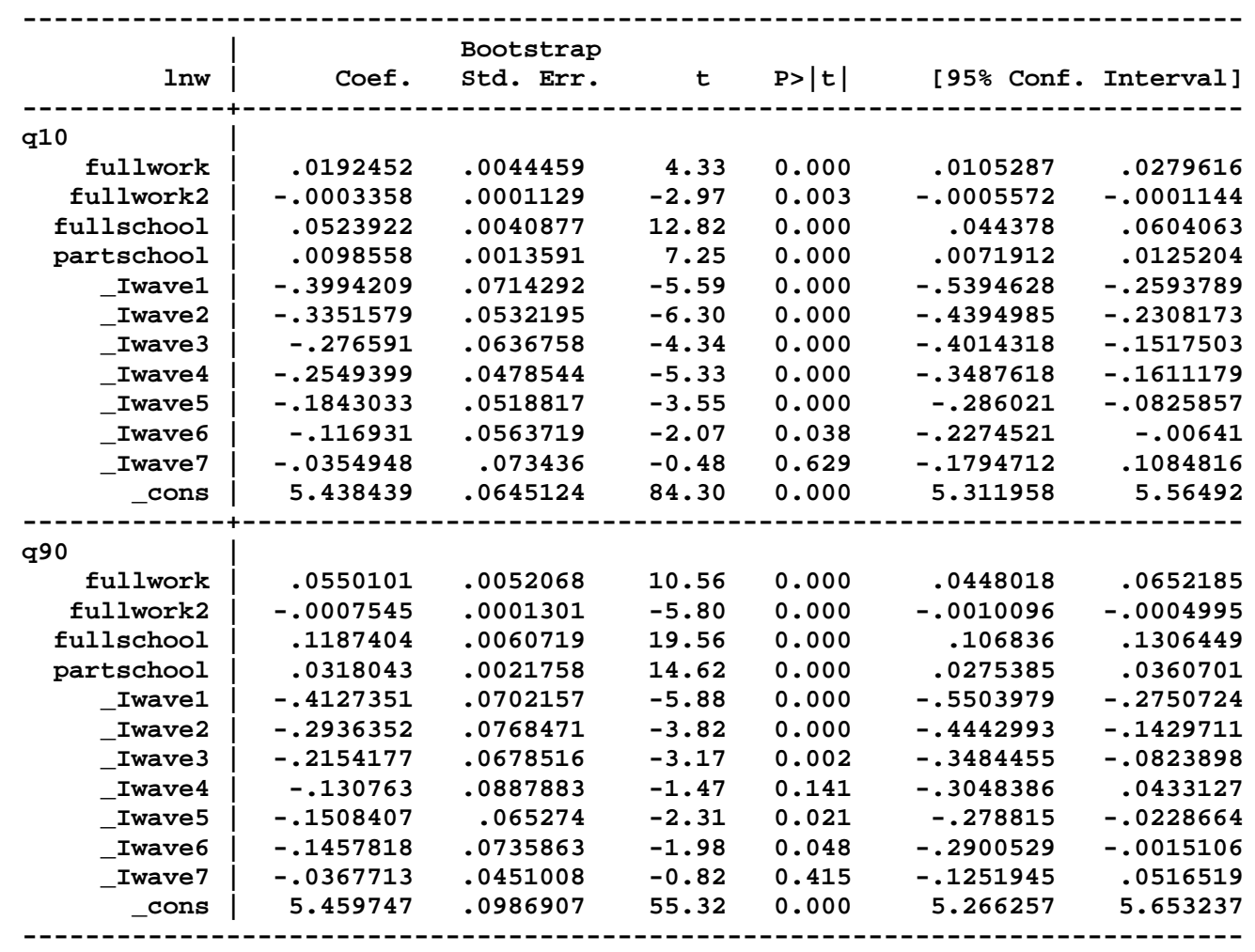

test $[q 10]$ fullschool $=[q 90]$ fullschool

$F(1,3918)=97.26$

Prob $>$ F $=0.0000$

test $[q 10]$ partschool $=[q 90]$ partschool

$F(1,3918)=100.05$

Prob $>F=0.0000$ 
Figure 1. Quantile regression
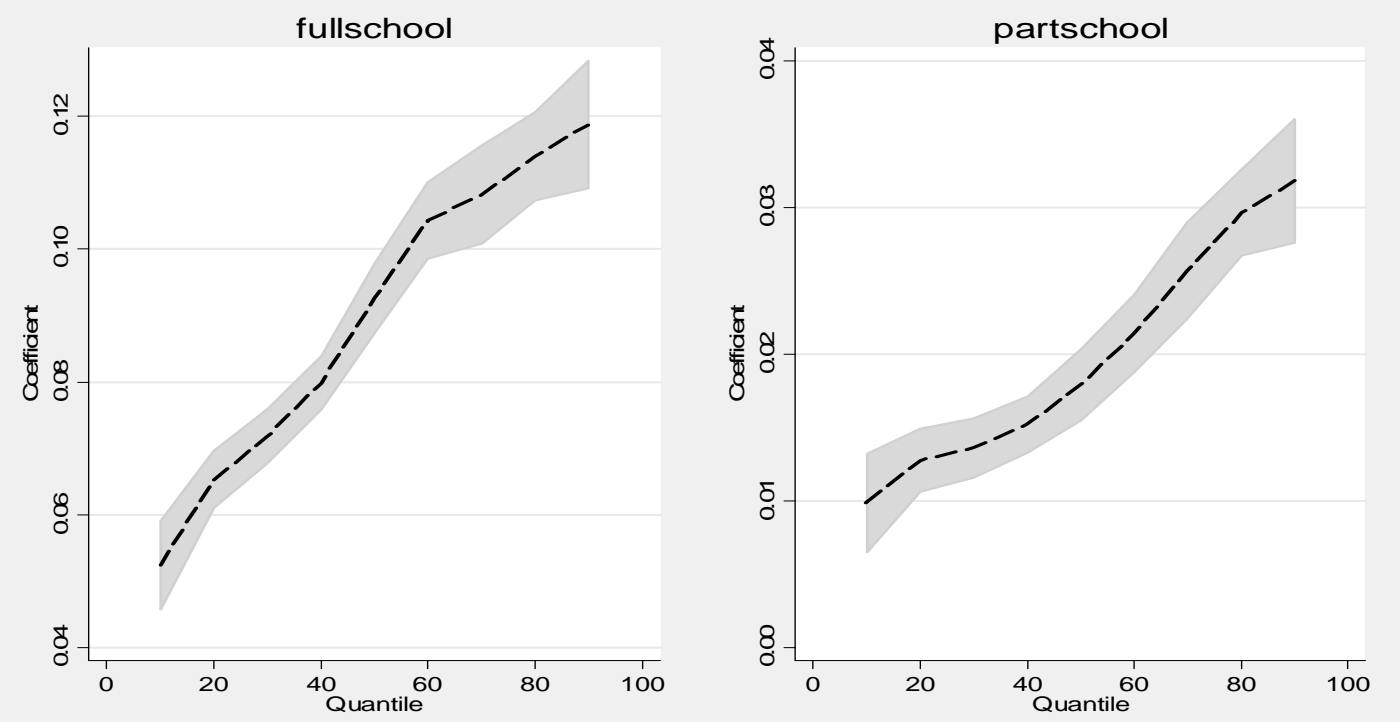